\title{
The smart book effect of pregnancy - postpartum care towards the husband's knowledge and reduction of reproductive health problems
}

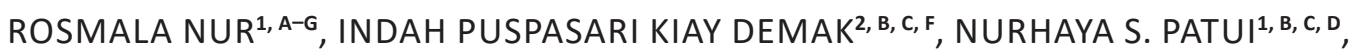
ORCID ID: 0000-0002-8693-0182

\author{
MUHAMMAD RUSYDI ${ }^{3, A, C-F}$, NENITA P. DOMINGO ${ }^{4, A, C-F}$, SYAIFUL HENDRA ${ }^{5,8-E}$ \\ ORCID ID: 0000-0003-3631-7686 ORCID ID: 0000-0002-0037-5895
}

HAJRA RASMITA NGEMBA ${ }^{6, \text { B-E }}$

ORCID ID: 0000-0001-8727-9267

${ }^{1}$ Public Health Department, Faculty of Public Health, Tadulako University, Palu, Indonesia

${ }^{2}$ Medical Department, Faculty of Medicine, Tadulako University, Palu, Indonesia

${ }^{3}$ Geophysics Department, Faculty of Mathematics and Natural Sciences, Tadulako University, Palu, Indonesia

${ }^{4}$ Asian Languages and Cultures Department, California University, California City, USA

${ }^{5}$ Informatic Study Programme, Department of Information Technology, Engineering Faculty, Tadulako University, Palu Indonesia

${ }^{6}$ Informatic Study Programme, Department of Information Technology, Engineering Faculty, Tadulako University, Palu Indonesia

A - Study Design, B - Data Collection, C - Statistical Analysis, D - Data Interpretation, E - Manuscript Preparation, F - Literature Search, G - Funds Collection

Summary Background. In the pregnancy-postpartum process, husbands play a very decisive and critical role. Poor decision making in relation to reproductive health for pregnant women in Central Sulawesi often causes delays in getting them to health services. This condition is one of the main causes of the high maternal mortality rate in Central Sulawesi.

Objectives. The purpose of this study is to examine the effect of the smart book about pregnancy-postpartum care on husbands' knowledge and the reduction of reproductive health problems.

Material and methods. This study used mixed methods (quasi-experiment and descriptive percentages). Quasi experiment employed a control group design, pre-test and post-test. Interventions using smart books on pregnancy-postpartum care were applied to the treatment group, while the control group was not given this option. A sample of 20 husbands for each group was taken, making a total sample of 40 people.

Results. There were differences in the scores of pre-test and post-test on the husbands' knowledge in the treatment group in relation to pregnancy $(p=0.000)$, childbirth $(p=0.000)$ and postpartum $(p=0.000)$ care. In the control group, there was no differences between pre-test and post-test scores in relation to pregnancy $(p=0.326)$, childbirth $(p=0.300)$ and postpartum $(p=0.129)$ care. In the treatment group, only $10 \%$ (2) of husbands had wives who experienced reproductive health problems (bleeding). Meanwhile, $45 \%$ (9) of the control group had wives who experienced reproductive health problems (bleeding, complications of pregnancy, miscarriage, low birth weight, fever/seizures and infant mortality).

Conclusions. The smart book of pregnancy-postpartum care increased husbands' knowledge and decreased wives' reproductive health problems.

Key words: reproductive health, postnatal care, knowledge.

Nur R, Demak IPK, Patui NS, Rusydi M, Domingo NP, Hendra S, Ngemba HR. The smart book effect of pregnancy - postpartum care towards the husband's knowledge and reduction of reproductive health problems. Fam Med Prim Care Rev 2020; 22(2): 133-139, doi: https://doi.org/10.5114/fmpcr.2019.90164.

\section{Background}

The 2012, Indonesian Demographic and Health Survey (IDHS) data [1] showed that the maternal mortality ratio in Indonesia ranks the highest in ASEAN countries, reaching 359 per 100,000 live births [1]. In Central Sulawesi, the maternal mortality ratio reached 358 per 100,000 live births, and in 2016, this ratio dropped to 208 per 100,000 live births. This ratio is still relatively high compared to other provinces in Indonesia. In Sigi Regency, the maternal mortality ratio is 309 per 100.000 deaths [2], one of the highest maternal mortality ratios in Central Sulawesi. Similarly, the infant mortality rate is 11 per 1,000 live births [1]. This data indicates the low reproductive health of mothers in Sigi Regency. Thus, it is necessary to discover the causal factors and possible solutions.

This high mortality ratio can be due to direct or indirect factors. The direct factors include bleeding, eclampsia, infection and pregnancy compilations $[1,2]$. Indirect factors encompass the completeness and accuracy of the implementation of antenatal care [3], the lack of blood tablet supplementation and haemoglobin examination that causes anaemia in pregnant 
women [4, 5], as well as a lack of knowledge about the signs of high risk pregnancy [6, 7]. In fact, pregnant women and their husbands can make preventive efforts to reduce the factors that are associated with maternal and infant mortality.

The Government of Central Sulawesi has made efforts to reduce the maternal mortality ratio (MMR) and infant mortality rate (IMR) through movements such as 'safe motherhood', 'making pregnancy safer' and 'simultaneous movement to decrease maternal mortality towards zero MMR'. However, these efforts are still top-down in nature and, under certain conditions, cannot be the main choice, as they have not touched upon the grassroots problem [8]. The issue of maternal mortality cannot be resolved merely using a medical approach but requires community participation [9]. It is very unlikely to reduce maternal mortality without innovative alternative efforts to increase community involvement in health development $[3,10]$.

In the pregnancy-postpartum process, the husbands' role is very decisive and needed $[11,12]$. Poor decision making in relation to reproductive health for pregnant women in Central Sulawesi often causes delays in getting them to health services and results in them being late for necessary treatments. This issue of maternal reproductive health can occur due to unequal power relations [13].

So far, pregnant women have received education and information about pregnancy-postpartum care through the book "maternal and child health", which is distributed to every pregnant woman by the Ministry of Health of the Republic of Indonesia [14]. The husbands have not received such education and information, even though they really need it. This research is aimed at examining models for improving reproductive health education and information for husbands in an effort to reduce maternal and infant mortality in the form of a smart book on pregnancy-postpartum care. This method is simple and easy to understand and does not amount to a high cost. This model is relatively new, since it involves husbands as the decision maker in the household. Pregnant women and their husbands need information and education that are easily understood and applied in pregnancy-postpartum care. If husbands have the knowledge and skills about pregnancy-postpartum care, their wives can undergo pregnancy and childbirth safely and comfortably. The results are a healthy baby delivery and a surviving mother. The husbands get knowledge and skill through reading a smart book of pregnant care contained one very useful achievement in family medication and primary care to improve maternal and child health.

\section{Objectives}

The purpose of this study is to examine the effect of the smart book about pregnancy-postpartum care on husbands' knowledge and on the reduction of reproductive health problems.

\section{Material and methods}

\section{Research design}

This study used a quantitative-qualitative mixed methods approach [15]. A quasi-experiment with a control group design, pre-test and post-test design approach was used to examine the effects of the smart book on husbands' knowledge about pregnancy-postpartum care. Meanwhile, a descriptive percentage design was used to assess its impact on reproductive health.

\section{Research sample}

Samples were taken using the non-probability sampling technique with the type of consecutive sampling in which the samples were selected if they met certain criteria. The sample in this study was husbands whose wives were in the second trimester of pregnancy ( $>4$ months), those willing to be a respondent and who were able to speak Indonesian. The treatment group and the control group had a sample of 20 people each. The total sample was 40 people. Interventions with the smart book were given to the treatment group, while the control group did not receive any treatment.

\section{Setting and time of research}

This research was carried out at the Tinggede community health centre, which encompassed the villages of Tinggede, South Tinggede and Sunju. The data was collected during a period of 6 months from June 2018 to December 2018.

\section{Indicator of variables}

The indicator of variables in this research can be seen in Table 1.

\begin{tabular}{|c|c|}
\hline Variable & Indicators \\
\hline $\begin{array}{l}\text { Knowledge differences } \\
\text { on pregnancy care }\end{array}$ & $\begin{array}{l}\text { Knowing the signs of pregnancy, providing regular and complete antenatal care (ANC), supplementing neces- } \\
\text { sary Fe tablets and taking } \mathrm{Hb} \text { examination, detecting the potential high-risks and dangers of pregnancy early, } \\
\text { maintaining healthy life behaviours, arousing a sense of calmness and happiness (not violence) during preg- } \\
\text { nancy, building a safe and responsible sexual relationship (using condoms and having relations only with one } \\
\text { sexual partner), preventing the spread of sexually transmitted disease (STDs) and sexually transmitted infec- } \\
\text { tions (STIs), deciding together (between husband and wife) to give birth at a modern health service provider. }\end{array}$ \\
\hline $\begin{array}{l}\text { Knowledge differences } \\
\text { on childbirth care }\end{array}$ & $\begin{array}{l}\text { Delivering to health services for childbirth, accompanying during the delivery process and supporting referral } \\
\text { efforts if necessary, expressing genuine love, providing necessary funds, providing necessary equipment and } \\
\text { transportation. }\end{array}$ \\
\hline $\begin{array}{l}\text { Knowledge differences } \\
\text { on postpartum care }\end{array}$ & $\begin{array}{l}\text { Ensuring the availability of nutritious food, encouraging the wife to breastfeed her baby immediately, helping } \\
\text { with household work that is quite heavy (drawing water, washing clothes, etc.), helping raise babies (bathing } \\
\text { babies, changing diapers, bringing babies for immunisation, etc.) and encouraging the wife to immediately } \\
\text { choose contraceptive methods. } \\
\text { Treatment was done by giving smart books and counselling to the treatment group. Health counselling was } \\
\text { carried out for approximately } 60 \text { minutes in the Sunju Village office space. Activities included orientation, } \\
\text { a simple and interesting presentation of the content of the smart book, discussion, question and answer ses- } \\
\text { sion and closing. After completion of counselling, interviews were held to collect data on the extent to which } \\
\text { their knowledge of pregnancy-postpartum care increased. On the last page of the smart book, they were given } \\
\text { a note that they must fill in about reproductive health problems experienced by their wives during pregnancy, } \\
\text { childbirth and postpartum periods and their responses to the incident. The book was collected again in early } \\
\text { December to find out the impact on reproductive health. Besides through books, researchers also observed } \\
\text { husbands' behaviour and their wives' reproductive health problems. }\end{array}$ \\
\hline
\end{tabular}




\begin{tabular}{|l|l|}
\hline Table 1. Indicator of variables \\
\hline Variable & Indicators \\
\hline Perception & $\begin{array}{l}\text { A husband's opinion on smart book postpartum pregnancy care after reading the book consists of two percep- } \\
\text { tions - good and not good. }\end{array}$ \\
\hline Duration of reading & $\begin{array}{l}\text { The length of time it takes for a husband to read a smart book for postpartum pregnancy care consists of two } \\
\text { choices (long, if reading takes more than } 30 \text { minutes, and not long, if reading takes less than } 30 \text { minutes). }\end{array}$ \\
\hline Frequency of reading & $\begin{array}{l}\text { How often do husbands read smart books on postpartum pregnancy care, consisting of two choices (often, if } \\
\text { the husband reads 3 times a week, and not often, if the husband reads less than 3 times a week). }\end{array}$ \\
\hline $\begin{array}{l}\text { Impact on wife's repro- } \\
\text { ductive health }\end{array}$ & $\begin{array}{l}\text { Measuring the percentage of impact on the wife's reproductive health, namely bleeding, infant mortality, } \\
\text { complications of pregnancy, low birth weight, fever/seizures and miscarriages. }\end{array}$ \\
\hline
\end{tabular}

\section{Data collection technique}

The data was collected using a questionnaire on knowledge about pregnancy, childbirth and postpartum care and its impact on reproductive health. The smart book on pregnancy-postpartum care was written and designed by the researchers. This book contained things that a husband should know during the pregnancy-postpartum period.

Data collection from the control group was carried out in the second week of June, and data on the impact on reproductive health was also collected in early December 2018. The data was analysed using a paired $t$-test and descriptive percentage. Analysis of the $t$-test was suitable to notice any difference before and after treatment in the two groups (control-treatment) [15]. The treatment group only becomes the unit of analysis for in-depth explanation about the smart book towards husbands in pregnancy-postpartum care.

\section{Ethical consideration}

The Ethics Committee of the Medical and Health Research Tadulako University declared that the research protocol proposed by the research team was in accordance with the ethical principles of research based on the ethical principles of the Helsinki Declaration in 2008. The Ethics Committee confirmed this under the number $4365 /$ UN28.1.30/KL/2018 on 14 January 2018.

\section{Results}

\section{The effects of the smart book on pregnancy-post- partum care on husbands' knowledge}

\section{Pregnancy care}

The average score of husbands' knowledge about pregnancy care in the treatment group was 71.63 in the pre-test and 93.60 in the post-test, with the statistical test showing a value of $p=0.000$. There was a significant difference between the average increase in the score of knowledge before and after being given the smart book in the treatment group (Table 2). Meanwhile, in the control group, the pre-test score was 74.93, and the post-test score was 75.19 , with the value of $p=0.326$ indicating that there was no significant difference between the average increase in the value of knowledge in the control group (Table 2).

\begin{tabular}{|c|c|c|c|c|}
\hline \multirow[t]{2}{*}{ Groups } & \multicolumn{2}{|c|}{ Average Scores } & \multirow[t]{2}{*}{ SD } & \multirow[t]{2}{*}{$p$} \\
\hline & Pre-test & Post-test & & \\
\hline Treatment & 71.63 & 93.60 & 7.712 & 0.000 \\
\hline Control & 74.93 & 75.19 & 1.095 & 0.326 \\
\hline
\end{tabular}

\section{Childbirth care}

Table 3 shows that the average score of husbands' knowledge about birth care was 70.40 in the pre-test and 92.30 in the post-test, with the statistical test showing a value of $p=0.000$. There was a significant difference between the average increase in the score of knowledge before being given the smart book and after being given the smart book in the treatment group. In the control group, the pre-test score was 76.70, and the post-test score was 77.07, with the value of $p=0.300$ indicating that there was no significant difference between the average increase in the score of knowledge in the control group.

Table 3. Knowledge differences on childbirth care before and after the smart books being given to the treatment group and control group

\begin{tabular}{|l|l|l|l|l|}
\hline \multirow{2}{*}{ Groups } & \multicolumn{2}{|l|}{ Average Scores } & \multirow{2}{*}{ SD } & \multirow{2}{*}{$p$} \\
\cline { 2 - 3 } & Pre-test & Post-test & & \\
\hline Treatment & 70.40 & 92.30 & 6.337 & 0.000 \\
\hline Control & 76.70 & 77.07 & 1.903 & 0.300 \\
\hline
\end{tabular}

\section{Postpartum care}

The average score of husbands' knowledge about postpartum care was 70.57 in the pre-test and 92.30 in the post-test, with the statistical test showing a value of $p=0.000$. There was a significant difference between the average increase in the score of knowledge before being given the smart book and after being given the smart book in the treatment group (Table 4). In the control group, the pre-test score was 75.47, and the post-test score was 75.93, with the value of $p=0.129$ indicating that there was no significant difference between the average increase in the score of knowledge in the control group (Table 4).

Table 4. Knowledge differences on postpartum care before and after the smart books being given to the treatment group and control group

\begin{tabular}{|l|l|l|l|l|}
\hline \multirow{2}{*}{ Groups } & \multicolumn{2}{|l|}{ Average Scores } & SD & \multirow{2}{*}{$p$} \\
\cline { 2 - 3 } & Pre-test & Post-test & & \\
\hline Treatment & 70.57 & 92.30 & 7.090 & 0.000 \\
\hline Control & 75.47 & 75.93 & 1.634 & 0.129 \\
\hline
\end{tabular}

The relationship of perception, duration of reading, and frequency of reading the smart book

Table 5 shows that the percentage of good perception and also good knowledge is $84.6 \%$ of husband and not good knowledge is only $15.4 \%$. Statistically, the relationship between perception of the smart book and the knowledge of care pregnant-postpartum is given by $p$-value of 0.004 . Long-time of reading duration increase the good knowledge with the percentage of $90.9 \%$. The $p$-value of 0.003 shows a higher relationship between length of reading and the knowledge of smart books of pregnancy-postpartum care. Often reading of smart book gave good knowledge of $83.3 \%$ and $p$-value of 0.015 . 


\begin{tabular}{|c|c|c|c|c|c|c|}
\hline \multirow[t]{2}{*}{ Group } & \multicolumn{5}{|c|}{ Knowledge $(n=20)$} & \multirow[t]{2}{*}{$p$} \\
\hline & Good & $\%$ & Not good & $\%$ & Result & \\
\hline $\begin{array}{l}\text { Perception } \\
\text { Good } \\
\text { Not good }\end{array}$ & $\begin{array}{l}11 \\
1 \\
\end{array}$ & \begin{tabular}{|l|}
84.6 \\
14.3 \\
\end{tabular} & $\begin{array}{l}2 \\
6 \\
\end{array}$ & $\begin{array}{l}15.4 \\
85.7\end{array}$ & $\begin{array}{l}13 \\
17 \\
\end{array}$ & 0.004 \\
\hline $\begin{array}{l}\text { Duration of reading } \\
\text { Long } \\
\text { Not long }\end{array}$ & $\begin{array}{l}10 \\
2 \\
\end{array}$ & $\begin{array}{l}90.9 \\
22.2\end{array}$ & $\begin{array}{l}1 \\
7 \\
\end{array}$ & \begin{tabular}{|l|}
9.1 \\
77.8
\end{tabular} & $\begin{array}{l}11 \\
9 \\
\end{array}$ & 0.003 \\
\hline $\begin{array}{l}\text { Frequency of reading } \\
\text { Often } \\
\text { Not often }\end{array}$ & $\begin{array}{l}10 \\
2\end{array}$ & \begin{tabular}{|l}
83.3 \\
25
\end{tabular} & $\begin{array}{l}2 \\
6\end{array}$ & $\begin{array}{l}16.7 \\
75\end{array}$ & $\begin{array}{l}12 \\
8\end{array}$ & 0.015 \\
\hline
\end{tabular}

\begin{tabular}{|c|c|c|c|c|c|c|c|c|c|c|c|c|c|c|c|c|}
\hline \multirow{4}{*}{$\begin{array}{l}\text { Smart Book } \\
\text { Intervention }\end{array}$} & \multicolumn{14}{|c|}{ Experienced and not experienced $(n=40)$} & \multirow{3}{*}{\multicolumn{2}{|c|}{ Total }} \\
\hline & \multicolumn{12}{|c|}{ Experienced $n=2(10 \%)$ of members } & \multirow{2}{*}{\multicolumn{2}{|c|}{$\begin{array}{l}\text { Not experi- } \\
\text { enced }\end{array}$}} & & \\
\hline & \multicolumn{2}{|c|}{ Bleeding } & \multicolumn{2}{|c|}{\begin{tabular}{|l} 
Infant Mor- \\
tality
\end{tabular}} & \multicolumn{2}{|c|}{$\begin{array}{l}\text { Complica- } \\
\text { tions of } \\
\text { Pregnancy }\end{array}$} & \multicolumn{2}{|c|}{$\begin{array}{l}\text { Low Birth } \\
\text { Weight }\end{array}$} & \multicolumn{2}{|c|}{$\begin{array}{l}\text { Fever/Sei- } \\
\text { zures }\end{array}$} & \multicolumn{2}{|c|}{ Miscarriage } & & & & \\
\hline & $n$ & $\%$ & $n$ & $\%$ & $n$ & $\%$ & $n$ & $\%$ & $n$ & $\%$ & $n$ & $\%$ & $n$ & $\%$ & $n$ & $\%$ \\
\hline Treatment & 1 & 5.0 & 0 & 0 & 0 & 0 & 0 & 0 & 1 & 5.0 & 0 & 0 & 18 & 90.0 & 20 & 100 \\
\hline & \multicolumn{12}{|c|}{ Experienced $n=9(45 \%)$ of members } & \multicolumn{2}{|c|}{$\begin{array}{l}\text { Not experi- } \\
\text { enced }\end{array}$} & & \\
\hline Control & 3 & 15.0 & 1 & 5.0 & 2 & 10.0 & 1 & 5.0 & 1 & 5.0 & 1 & 5.0 & 11 & 55.0 & 20 & 100 \\
\hline Total & 4 & 20.0 & 1 & 5.0 & 2 & 10.0 & 1 & 5.0 & 1 & 1.0 & 1 & 5.0 & 29 & 72.5 & 40 & 100 \\
\hline
\end{tabular}

\section{The impact on wives' reproductive health problems}

In the treatment group, $90 \%$ (18) of members' wives did not experience reproductive health problems. The remaining $10 \%$ (2) experienced a disorder consisting of bleeding 5\% (1) and fever/seizures 5\% (1) (Table 6). Meanwhile, in the control group, those who did not experience reproductive health problems amounted to $55 \%$ (11), and the remaining $45 \%$ (9) experienced bleeding $15 \%(3)$, pregnancy complications $10 \%$ (2), miscarriages $5 \%(1)$, low birth weight $5 \%(1)$, fever/seizures $5 \%(1)$ and infant mortality $5 \%$ (1).

This data was supported by a statement from Mrs. P, the wife of the respondent, who said, "After my husband participated in the workshop and was given a smart book on maternity care, my husband became aware of ANC examinations, signs of pregnancy and high-risk pregnancy".

The same thing was said by Mr. AY: "Yes, the book was very useful, because it became a guideline for me about what I should do during pregnancy, during childbirth and after childbirth".

\section{Discussion}

\section{a. Knowledge differences on pregnancy care before and after being given smart books}

The results of statistical tests showed that there were differences in the scores of husbands' knowledge about pregnancy care before and after being given the smart book, with a value of $p=0.000$. Meanwhile, the control group showed no difference in the scores of pre-test and post-test, with $p=$ 0.326 (Table 2). There was a significant increase in the scores of pregnancy care knowledge after being given the smart book. This happened because, since they were married, the husbands had never received any counselling about their roles in pregnancy care, primarily about ANC services by health workers in the region. Thus, the information obtained by the husband about reproductive health was very little. This result was in line with a finding [15] showing that the knowledge of pregnancy care and about antenatal care was aimed to provide husbands with information, understanding and goals about "10T" antenatal care (measuring body weight and height, blood pressure examination, measurement of fundal height, administration of TT immunisation, use of Fe tablets, measurement of upper arm circumference, haemoglobin checking, early detection of high-risk pregnancy, case management and counselling). Husbands' lack of knowledge about the importance of antenatal care to pregnant women often results in the exclusion of antenatal care during pregnancy. Being given the smart book turned out to be helpful in increasing their knowledge and support during antenatal care. The information in the smart book greatly guided the husbands in the treatment group to take care of their wives during the pregnancy period. The model of communication, information and education provided in the book for husbands influenced and invited them to maintain healthy behaviours. It indicated that the husbands tried to get to know how to take care of their wives during pregnancy and prevent things that might harm pregnant women. Increasing husbands' knowledge about antenatal care is very important in maintaining the health of pregnant women. Another study [16] similarly found that there was an influence of health information on changing the knowledge, attitudes and behaviour of husbands towards reproductive health. Changes in husbands' attitudes and behaviour will influence the patriarchal cultural order (men have been deemed to be the proprietor of 'power' that determines the direction of 'knowledge discourse' of society) [17]. Patriarchal culture including the dominant power of the husband, a form of male pressure on female sexuality and fertility of husband [pater] or oldest man [patriarch] has absolute power in the family. So that, the woman in the family becomes under his authority [14]. The smart book of pregnancy-postpartum care for the husband builds a balanced relationship between the father-mother, who work through the discourse of knowledge in social interaction, which then gives birth to a culture of equality in pregnancy care. It will improve the healthy literacy level for the husband since all this time the husband only considers that the care for pregnant-postpartum is only his wife's concern $[5,9]$. 
The lack of knowledge among husbands (before treatment) was also due to their assumption that pregnancy care was merely a woman's problem, and thus their awareness of the information related to maternity care was very low. The findings in another research [8] similarly showed that there was a gender gap in relation to reproductive health in pregnant women and that husbands often did not care about their wives' pregnancy.

\section{b. Knowledge differences on childbirth care before and after being given smart books}

The results of the statistical tests showed differences in the scores of husbands' knowledge about childbirth care before and after being given the smart book, with a value of $p=0.000$. In contrast, the control group did not show any differences in the pre-test and post-test scores, with a value of $p=0.300$ (Table 3). These differences occurred because the husband assumed that the immediate family of the wife could accompany the wife. In this case, it is the mother, sister or aunt. The husbands' job was only to pay for the cost of labour. The needs for love, care and assistance were fully handed over to immediate family members. After being given the smart book, the husband realised the importance of bringing his wife to a health care centre for childbirth, assisting during the delivery process, supporting referral efforts if needed, expressing love, providing necessary funding and providing necessary equipment and transportation. Another study $[17,18]$ about the effect of health education on changes in the knowledge and attitudes of husbands about childbirth care also showed similar findings.

Efforts to increase husbands' knowledge about childbirth care include holding meetings, orientation and advocacy. Besides increasing husbands' knowledge, it also need development attitudes and awareness of gender equality. Moreover, the places of service and consultation of childbirth care should be increased $[12,13]$.

\section{c. Knowledge differences on postpartum care befo- re and after being given smart books}

The results of statistical tests showed that there were differences in the husbands' knowledge scores about postpartum care before and after being given the smart book, with a value of $p=0.000$. Meanwhile, the control group did not obtain any different score in the pre-test and post-test, with a value of $p=$ 0.129 (Table 4). This happened because the husbands did not know the importance of postpartum care and its impact on maternal and infant health (such as the "baby blues" syndrome, postpartum syndrome, infection, postpartum haemorrhaging and lack of red blood cells), which has an impact on maternal and infant mortality. After being given the treatment, the husband knew and realised that the role of a husband in the postpartum period was to help his wife in doing heavy household work (drawing water, washing clothes), raising babies (bathing the baby, changing diapers, bringing babies for immunisation), ensuring the availability of nutritious food, encouraging his wife to immediately breastfeed her baby and encouraging her to immediately choose a contraceptive method. This result was consistent with studies [19] which found that there was an effect of health education on changes in husbands' knowledge and attitudes about postpartum care after being given treatment. This study found that husbands' knowledge was closely related to the health level of pregnant women, especially during the childbirth and postpartum period.

\section{The relationship of perception, duration of reading and frequency of reading the smart books}

The involvement and responsibility of the husband needs to prosper between a husband and wife in the context of reproductive health. The role of the husband towards a pregnant wife start from checking the pregnancy to health workers. A husband's knowledge about pregnancy and danger signs is essential to avoid the occurrence of pregnancy complications and the mortality of mothers and babies [20].

The results of the statistical tests show that the perception, length of read and the frequency of reading the smart book had a relationship with husbands' knowledge about pregnant-parturition in the control group (Table 5). By reading the smart book, husbands can increase knowledge and skill about pregnant-postpartum care. The smart book contains about 10 minimum service standard in pregnancy. Because most of husbands' knowledge about pregnancy is still low, most husbands only know nausea and vomiting, as well as no menstruation, as signs of pregnancy. However, most them do not know of any physical sign that occurs in mothers who hail as piss often, breasts taut, unconscious, varicose veins, and the presence of pigmentation on the skin as signs of pregnancy. By reading the smart book, husband can perform tasks and well responsibilities [21].

The factor that affects the involvement of a husband in pregnancy care is the level of knowledge. A husband's lack of knowledge about pregnancy-childbirth care is one of the causes of the low participation of a husband in the discharge of duties and responsibilities [20].

\section{Impact on the reduction of reproductive health problems}

There was a decrease in the reproductive health problems in the treatment group compared to the control group (Table 6). Complications of pregnancy, miscarriage and low birth weight did not occur in the treatment group, while in the control group, all of these problems occurred. This happened because the husbands had a smart book about what to do when their wives were in the pregnancy, childbirth and postpartum periods. Husbands knew about signs of pregnancy, high-risk pregnancy, benefits of antenatal care and where to look for help. Other studies [19, 22] similarly found that husbands who had knowledge would change their thinking patterns and behaviour, and as a result, this influenced their actions. Likewise, another research [14] showed that women experienced delayed treatments from health workers because of a lack of the husband's support.

Wives who did not feel loved during the pregnancy-postpartum periods experienced pregnancy complications both directly and indirectly. This finding was in line with a study [22, 23] that focused on examining violence by husbands during the pregnancy of Thai women. Studying 475 pregnant women, the research found that women experienced violence during pregnancy in the form of sexual violence $(13.1 \%(61))$ and physical violence $(4.8 \%(19))$. Violence during pregnancy significantly affected the sense of unwanted pregnancies, complications of pregnancy, increased symptoms of depression, premature birth/low birth weight, inadequate antenatal care, the spread of sexually transmitted diseases and the occurrence of maternal deaths. Likewise, other studies $[23,24]$ revealed that violence that occurred to wives, in addition to causing pregnancy complications, also indicated that there was a sign of neglecting the sexuality rights and reproductive health of women.

Another interesting phenomenon found at the location of the study before being given treatment was the low use of contraception by the wives. This also happened because of the high dominance of husbands in a family's decision-making process. A similar situation happened in Latin America, where husbands' indifferent attitudes to family planning was related to the value of machismo, a very high value of manliness, assuming that the husband was more dominant in determining something in the family $[25,26]$. Thus, the husband has an important role in protecting the health of the mother and her children. A husband, as the head of the household, must know the signs of danger during the pregnancy, childbirth and postpartum periods in the hope that it will prevent any delays in recognising danger signs 
and in getting adequate health assistance, which has an impact on reducing wives' reproductive health problems.

\section{Limitations of the study}

The presented research is limited in number of sample. It is important to expand the sample research group in the future.

\section{Conclusions}

The smart book on postpartum care increased the knowledge of husbands on pregnancy, childbirth and postpartum care. This brought about an impact on the reduction of the reproductive health problems of their wives. It is expected that in the future this book can be replicated in other regions, so that the knowledge of husbands and wives is balanced in pregnancy-postpartum care to reduce maternal and infant mortality in Central Sulawesi.

Source of funding: This work was funded by Ministry of Research and Higher Education of the Republic of Indonesia for the research funding 2018.

Conflicts of interest: The authors declare no conflicts of interest.

\section{References}

1. Survey Indonesian demographic and health survey. 2012 Jakarta Indonesia. Calverton (MA) Macro, International; 2012.

2. Delayed progress: 2016 maternal child marriage data analysis in Indonesia. Jakarta: Central Bureau of Statistics (Indonesia); 2016.

3. Maswime S, Buchmann E. Causes and avoidable factors in maternal death due to cesarean-related hemorrhage in South Africa. Int J Gynecol Obstet 2016; 134(3): 320-323.

4. Kaneko H, Honjo S. The psychometric properties and factor structure of the postpartum bonding questionnaire in Japanese mothers. Psychology 2014; 5(9): 1135-1142, doi: 10.4236/Psych.2014.59126.

5. Gedefaw L, Ayele A, Asres Y, et al. Anemia and associated factors among pregnant women attending antenatal care clinic in Wolaita Sodo Town, Southern Ethiopia. Ethiop J Health Sci 2015; 25(2): 155-162, doi: 10.4314/ejhs.v25i2.8.

6. Khashab S, El Beltagy NS, Badie D. Maternal morbidity and mortality in ElShatby and Dar Ismail maternity hospitals in Alexandria: a comparative study. Alexandria J Med 2018; 54(1): 63-67, doi: 10.1016/j.ajme.12.003.

7. Zeballos Sarrato S, Villar Castro S, Ramos Navarro C, et al. Risks factors associated with intra-partum foetal mortality in pre-term infants'. Anales de Pediatría (English edition). J Asoc Española Pediatría 2017; 86(3): 127-134.

8. Susilo D. Compliance with the implementation of hand hygiene activities at health workers in X Hospital Surabaya. J Wiyata 2015; 2(2): 200-204.

9. Nur R, Darwin M, Maria A. Hegemony of men and violence against women during pregnancy-post childbirth in Sigibiromaru and Donggala Regency, Central Sulawesi. IJSBAR 2017; 4531: 299-312.

10. Pillay T, Porter K, Marson S. Developing an early life Parent Education Programme in response to high infant mortality rates. $J$ Neonatal Nurs 2017; 23(5): 1-2, doi: 10.1016/j.jnn.2017.02.005.

11. Sukmo R, Islamudin RA, Subha I, et al. ICE (Intensive Community Empowerment) as a solution to prevent increase in maternal mortality rate (MMR) as a pilot program in the Bangetayu Wetan Kelurahan, Semarang City. Student Scientific Magazine 2014; 4: 12-17.

12. Marchie CL. Socio-cultural factors as correlates of maternal mortality in Edo South Senatorial District, Nigeria. Asian Pacific J Reprod 2012; 1(4): 315-317, doi: 10.1016/S2305-0500(13)60100-1.

13. Nur R. Developing local culture potential as the model alternative of girls protection. Int SAMANM J Mark Manag 2016; 4(14): 1-10.

14. Nur R. Impacts of violence during pregnancy - post childbirth to reproductive health of women at rural and urban areas. Int J Sci Basic Appl Res 2015; 4531: 16-26.

15. Nur R, Mallongi A. Research article impact of violence on health reproduction among wives in Donggala. Pakistan Journal of Nutrition 2018; 17(1): 8-14, doi: 10.3923/pjn.2018.8.14.

16. Kyilleh JM, Tabong PTN, Konlaan BB. Adolescents' reproductive health knowledge, choices and factors affecting reproductive health choices: a qualitative study in the West Gonja District in Northern region, Ghana. BMC Int Health Hum Rights 2018; 18(1): 1-12.

17. Rahman AE, Perkins J, Islam S, et al. Knowledge and involvement of husbands in maternal and newborn health in rural Bangladesh. BMC Pregnancy Childbirth 2018; 18(1): 247, doi: 10.1186/s12884-018-1882-2.

18. Nur R, Mallongi A, Indah P Kiyai Demak, et al. Early age married and impact of healt reproduction women. Journal of Engineering and Applied Sciences 2019; 14: 981-986, doi: 10.36478/jeasci.2019.981.986.

19. Demmler JC, Hill RA, Rahman MA, et al. Educational attainment at age 10 e 11 years predicts health risk behaviors and injury risk during adolescence. J Adolesc Health 2017; 61(2): 212-218, doi: 10.1016/j.jadohealth.2017.02.003.

20. Thapa DK, Niehof A. Women's autonomy and husbands' involvement in maternal health care in Nepal. Soc Sci Med 2013; 93: 1-10, doi: 10.1016/j.socscimed.2013.06.003.

21. Carter M. Husbands and maternal health matters in rural Guatemala: wives' reports on their spouses' involvement in pregnancy and birth. Soc Sci Med 2002; 55(3): 437-450.

22. Sapkota S, Kobayashi T, Takase M. Husbands' experiences of supporting their wives during childbirth in Nepal. Midwifery 2012; 28(1): 45-51, doi: 10.1016/j.midw.2010.10.010.

23. Sialubanje C, Massar K, Kirch EM, et al. Husbands' experiences and perceptions regarding the use of maternity waiting homes in rural Zambia. Int J Gynecol Obstet 2016; 133(1): 108-111, doi: 10.1016/j.ijgo.2015.08.023.

24. Thananowan N, Heidrich SM. Intimate partner violence among pregnant Thai women. Violence Against Women 2008; 14(5): 509-527.

25. Frech A. Advances in life course research healthy behavior trajectories between adolescence and young adulthood. Adv Life Course Res 2012; 17(2): 59-68, doi: 10.1016/j.alcr.2012.01.003.

26. Pallitto CC, García-Moreno C, Jansen HA et al. Intimate partner violence, abortion, and unintended pregnancy: results from the WHO Multi-country Study on women's health and domestic violence. Int J Gynecol Obstet 2013; 120(1): 3-9, doi: 10.1016/j.ijgo.2012.07.003.

Tables: 6

Figures: 0

References: 26 
Address for correspondence:

Rosmala Nur, PhD

Population and Reproductive Health

Tadulako University

Soekarno-Hatta Street KM. 9

Palu, Central Sulawesi

Indonesia

Tel.: +62 85292267775

E-mail: rosmalanur.fkm@untad.ac.id, nurrosmala09@gmail.com 